\title{
Reengagement in Meaningful Occupations During the Transition From Hospital to Home for People With Acquired Brain Injury and Their Family Caregivers
}

\author{
Benjamin Turner, Tamara Ownsworth, Petrea Cornwell, \\ Jennifer Fleming
}

\section{KEY WORDS}

- brain injuries

- human activities

- life change events

- motivation
Benjamin Turner, 0T, is Doctoral Candidate, Division of Occupational Therapy, School of Health and Rehabilitation Sciences, Therapies Building (84a), University of Queensland, St. Lucia, Queensland 4072 Australia; b.turner2@uq.edu.au

Tamara Ownsworth, PhD, is Senior Research Fellow, School of Psychology, Griffith University, Nathan Campus, Queensland, Australia.

Petrea Cornwell, PhD, is Conjoint Research Fellow, School of Health and Rehabilitation Sciences, University of Queensland; and Princess Alexandra Hospital, Woolloongabba, Brisbane, Queensland 4102 Australia.

Jennifer Fleming, PhD, is Senior Conjoint Research Fellow, School of Health and Rehabilitation Sciences, University of Queensland; and Princess Alexandra Hospital, Woolloongabba, Brisbane, Queensland 4102 Australia.
OBJECTIVE. To explore people's lived experiences of reengagement in meaningful occupations during the hospital-to-home transition phase after acquired brain injury (ABI).

METHOD. Participants included 20 people with $A B I$ and 18 family caregivers. On the basis of a phenomenological approach, data collection entailed in-depth semistructured interviews at predischarge and 1 and 3 months postdischarge. Thematic analysis of interview transcripts involved open, axial, and selective coding techniques.

RESULTS. Two primary themes emerged from the analysis: desired versus actual participation and struggle for independence. Theme 1 depicts the key occupations of importance to people and their caregivers during transition and explores desired and actual participation in occupations. Theme 2 highlights the struggle to regain independence and the differing perspectives of the 2 participant groups concerning this process.

CONCLUSION. Clinical practice implications relate to client-centered goal setting, contexts and environments in which therapy occurs, and provision of information to patients and families.

Turner, B., Ownsworth, T., Cornwell, P., \& Fleming, J. (2009). Reengagement in meaningful occupations during the transition from hospital to home for people with acquired brain injury and their family caregivers. American Journal of Occupational Therapy, 63, 609-620.

0 ccupation is integral to both the underlying philosophy and the everyday practice of occupational therapy. Concern for the occupational nature of human beings was fundamental to the establishment of the occupational therapy profession (Gray, 1998; Pierce, 2001). Occupation is defined as the ordinary and extraordinary things people do in their day-to-day lives to occupy time, maintain well-being, and contribute to society, and it includes active participation in self-maintenance, work, leisure, and play (American Occupational Therapy Association, 1995; Crepeau, Cohn, \& Schell, 2008). A person's ability to participate in meaningful occupations can be significantly compromised by serious injury, trauma, or both. In particular, after acquired brain injury (ABI), many people experience difficulties reengaging in meaningful occupations, especially during the transition from hospital to home (Turner et al., 2007).

Transitions refer to passages from one life phase, condition, or status to another and typically involve changes in roles, relationships, abilities, identities, or patterns of behavior (Schlossberg, 1984). Transitions can therefore result in changes to occupational roles and participation. For example, in a study of the transition to community living after discharge from the hospital for varying health-related concerns, Gage, Cook, and Fryday-Field (1997) identified that although participants $(n=27)$ placed great importance on the need to participate in occupations during 
the transition process, many were unable to resume meaningful occupations such as driving and domestic tasks. Additionally, they identified three themes relevant to dimensions of occupation: (1) the importance of doing, (2) recognizing abilities and limits, and (3) grieving the loss of independence and control in occupations (Gage et al., 1997).

The transition from hospital to home has been identified as a critical phase of the rehabilitation continuum after $\mathrm{ABI}$ because it marks the commencement of the community reintegration process (McCabe et al., 2007; Turner et al., 2007). During this phase, many people begin to comprehend their injuries' impact as they attempt to reengage in meaningful occupations (Fleming, Connell, Tooth, \& Strong, 2002; McColl et al., 1998, 1999; Turner et al., 2007). Research has suggested that the transition phase is typically perceived by people with $\mathrm{ABI}$ and their family caregivers as an exciting yet difficult time and, as such, postdischarge follow-up support is crucial (Turner, Fleming, Ownsworth, \& Cornwell, 2008). Other studies have highlighted that the transition phase is characterized by improved psychosocial functioning (McCarthy et al., 2006) and ongoing emotional adjustment (Anson \& Ponsford, 2006). Despite this, little is known about people's lived experiences of reengagement in meaningful occupations during the transition phase. Furthermore, the key occupations of importance to people with ABI during this phase have yet to be identified.

Previous research has, however, provided some insight into people's lived experiences of the process of transition from hospital to home (McColl et al., 1998, 1999; Turner et al., 2007). In a retrospective, qualitative study of the transition from hospital to home of people with ABI $(n=13)$ and their family caregivers $(n=11)$, Turner et al. (2007) identified two main factors as being integral to the success of the transition process: (1) facilitation of opportunities to engage in meaningful occupations and (2) coordinated service delivery, including access to outpatient or communitybased rehabilitative therapy services, or both. Moreover, the capacity of families to provide adequate support was also seen as crucial to transition success, and consequently, caregiver support was emphasized as an important area for clinical practice. In a separate study on people's transition to independent living after $\mathrm{ABI}(n=4)$, which also included family caregiver $(n=4)$ and service provider $(n=12)$ perspectives, McColl et al. (1999) highlighted other factors, such as avoidance of drugs and alcohol, emotional and behavioral selfcontrol, and effective financial management, as being salient to transition success.

The role of occupational therapy within the $\mathrm{ABI}$ rehabilitation continuum is also well documented, with evidence supporting the benefits of occupational therapy intervention for improving performance on tasks of daily living (Barras,
2005; Fleming, Lucas, \& Lightbody, 2006; Phipps \& Richardson, 2007). For example, Phipps and Richardson (2007) evaluated the effects of outpatient occupational therapy for people with ABI $(n=155)$ on levels of performance and satisfaction with daily activities as measured by the Canadian Occupational Performance Measure (COPM) (Law et al., 1998). These authors found a significant improvement between admission and discharge in selfperceived performance and satisfaction with tasks of daily living, including self-care, home management, and leisure skills (Phipps \& Richardson, 2007). Several previous studies have likewise demonstrated improvement in ratings of performance and satisfaction on the COPM after occupational therapy intervention (Trombly, Radomski, \& Davis, 1998; Trombly, Radomski, Trexel, \& Burrnett-Smith, 2002). Moreover, occupational therapy intervention has been found to improve management of cognitive impairment (Barras, 2005) and self-awareness of deficits after ABI (Fleming et al., 2006).

Although the literature to date has generally highlighted the critical nature of the transition phase and the key role of occupational therapy in $\mathrm{ABI}$ rehabilitation, we did not locate research investigating people's lived experiences during the process of reengaging in meaningful occupations. Moreover, the literature is limited by a lack of ABI-specific studies (Gage et al., 1997), early transition studies (i.e., studies capturing the initial transition to home after inpatient rehabilitation; McCabe et al., 2007; McColl et al., 1998, 1999), and studies that use retrospective data collection techniques (Phipps \& Richardson, 2007; Turner et al., 2007). Given the limitations and gaps that currently exist in the literature and the integral role of occupational therapists in facilitating community reintegration during the transition phase, further research is clearly warranted. In this study, therefore, we address the following research questions:

- What occupations are most important to people with ABI and their family caregivers during the transition phase?

- How do people with ABI and their family caregivers perceive the process of reengagement in meaningful occupations during the transition from hospital to home?

\section{Method}

\section{Design}

We used a phenomenological approach that made use of a prospective longitudinal design. Phenomenology attempts to understand how the world appears from others' perspectives. We used this approach instead of alternative approaches (e.g., grounded theory, ethnography) because of our focus on people's subjective or lived experiences (Patton, 2002). 


\section{Participants}

Participants were recruited from an inpatient ABI rehabilitation unit at a major metropolitan hospital in Australia on a consecutive discharge basis until data saturation was reached. Saturation was identified as the stage at which no new data (i.e., major themes) emerged from the interviewing process and was determined through collaborative discussion between members of the research team (Patton, 2002). Participants were screened by their treating occupational therapist according to the following inclusion criteria: (1) diagnosis of ABI as documented in a medical report, (2) expectation of returning home after discharge from inpatient rehabilitation (i.e., not discharged to a care facility or other hospital), (3) $\geq 16$ years old, (4) adequate English communication skills to participate in an interview, and (5) capacity to provide informed consent. Participants were excluded if they had a premorbid neurological condition or psychiatric disorder.
During the 5-month recruitment period, 37 patients were discharged from the rehabilitation unit. Of these, 9 self-discharged against medical advice, 3 did not provide informed consent, and 5 did not meet the study's inclusion criteria. People with ABI who provided informed written consent $(n=20)$ were asked to identify a family member to participate in the study. Nominated family caregivers were then contacted by a member of the research team, who explained the details of the study and sought informed written consent from caregivers. The family caregiver of 1 participant with ABI did not provide informed consent. Moreover, 1 family caregiver who did provide informed consent was the primary caregiver of 2 participants with $\mathrm{ABI}$ who were husband and wife. Therefore, in total, participants included 20 people with $\mathrm{ABI}$ and 18 family caregivers. Family caregivers included 11 spouses or partners, 6 parents, and 1 sibling. A summary of key demographic and injuryrelated information for participants is provided in Table 1.

Table 1. Demographic and Injury-Related Information of Participants With Acquired Brain Injury (ABI) and Their Family Caregivers

\begin{tabular}{|c|c|c|}
\hline Demographic and Injury-Related Information & $\begin{array}{c}\text { Participants With ABI } \\
\text { ( } n[\%] \text { or } \\
M[S D], \text { Range); } n=20\end{array}$ & $\begin{array}{c}\text { Family Caregivers } \\
(n[\%] \text { or } \\
M[S D], \text { Range); } n=18\end{array}$ \\
\hline \multicolumn{3}{|l|}{ Gender } \\
\hline Male & $15(75)$ & $5(27.8)$ \\
\hline Female & $5(25)$ & $13(72.2)$ \\
\hline Age (years) & $40.2(14.5), 17-63$ & 46.63 (10.9), 24-65 \\
\hline \multicolumn{3}{|l|}{ Relationship status (at time of first interview) } \\
\hline In a relationship (married, de facto married) & $18(90)$ & $17(94.4)$ \\
\hline Not in a relationship & $2(10)$ & $1(5.6)$ \\
\hline \multicolumn{3}{|l|}{ Preinjury occupational status } \\
\hline Employed & $14(70)$ & $16(88.9)$ \\
\hline Unemployed & $1(5)$ & - \\
\hline Home duties & $3(15)$ & $2(11.1)$ \\
\hline Student & $2(10)$ & - \\
\hline \multicolumn{3}{|l|}{ Level of education } \\
\hline$\leq$ Grade 10 & $9(45)$ & $4(22.2)$ \\
\hline Completed high school & $3(15)$ & $5(27.8)$ \\
\hline Trade qualifications & $7(35)$ & $2(11.1)$ \\
\hline University—undergraduate & $1(5)$ & $7(38.9)$ \\
\hline \multicolumn{3}{|l|}{ Cause of injury } \\
\hline Traumatic brain injury & $16(80)$ & - \\
\hline Aneurysm or stroke & $4(20)$ & - \\
\hline \multicolumn{3}{|l|}{ Cause of traumatic brain injury $(n=16)$} \\
\hline Motor vehicle accident & $7(43.75)$ & - \\
\hline Motor bike accident & $1(6.25)$ & - \\
\hline Assault & $1(6.25)$ & - \\
\hline Fall & $4(25)$ & - \\
\hline Other & $3(18.75)$ & - \\
\hline Length of stay in rehabilitation (days) & 89.6 (71.2), 22-318 & - \\
\hline Length of stay in hospital (days) & 147.6 (157.6), 35-776 & - \\
\hline $\begin{array}{l}\text { Initial Glasgow Coma Scale (Teasdale \& Jennett, 1974) } \\
\text { score }(n=18)\end{array}$ & 8.5 (4.2), 3-15 & - \\
\hline Length of PTA (days; $n=13$ ) & 41.2 (23.5), 14-88 & - \\
\hline Disability Rating Scale (Rappaport, 2005; discharge) & 4.7 (1.8), 2-8 & - \\
\hline $\begin{array}{l}\text { FIM }^{\text {TM }} \text { (Uniform Data System for Medical Rehabilitation, } \\
\text { 1999; total score; discharge) total score (discharge) }\end{array}$ & 114.9 (9.76), 90-123 & - \\
\hline
\end{tabular}

Note. $M=$ mean; $S D=$ standard deviation; PTA = posttraumatic amnesia.

$-=$ specific demographic or injury-related information is not applicable. 


\section{Data Collection}

As is consistent with a phenomenological approach, the principal method of data collection entailed in-depth semistructured interviews, which were conducted with participants at the following time points during the transition phase: predischarge and 1 and 3 months postdischarge. Each semistructured interview followed a set of questions (i.e., an interview guide) that the research team developed on the basis of the members' extensive multidisciplinary clinical experience, a comprehensive review of ABI transition-specific literature (Turner et al., 2008), and the outcomes of a pilot investigation (Turner et al., 2007). Furthermore, the interview guide incorporated the guidelines proposed by Paterson and Scott-Finlay (2002) concerning principles of conducting in-depth interviews with an ABI population. The specific questions that made up the interview guide are displayed in Table 2.

Additional prompts were used throughout the interviews to support and encourage participants to elaborate on their responses. Moreover, we adapted the wording of all questions for the family caregiver interviews (e.g., "What activities has [person with ABI] done since coming home?").

\section{Table 2. Summary of Questions Included in the Interview Guide}

\begin{tabular}{ll}
\hline Time Frame & \multicolumn{1}{c}{ Questions } \\
\hline Predischarge & Discharge preparation: \\
& What has happened while you have been in hospi- \\
tal to help you get ready for going home? \\
Home expectations: \\
- How well do you feel that you will manage once \\
- Hou get home? \\
Have you thought about what you would like to do \\
like to do? \\
- What other activities would you like to do when \\
you get home? \\
- What things do you think that you may have dif- \\
ficulty with?
\end{tabular}

Postdischarge (1- and Hospital reflection:

3-month interviews) - What things do you feel helped you the most to prepare for coming home?

- Is there anything that you feel that could have been done better to help you prepare?

Life at home:

- What activities have you done since coming home?

- How do you spend most of your days?

- What's a typical day like for you?

- What has been the best thing about coming home?

- What has been the most difficult thing about coming home?

- What other things have you had difficulty with since coming home?

- How do you feel that coming home has influenced your recovery?
The semistructured format was designed to facilitate open dialogue as participants described their experiences during the transition process. All interviews were recorded using a digital recording device. Excluding the time for the initial rapport building and the postinterview debriefing, the average duration of interviews with participants with $A B I$ was $33 \mathrm{~min}$ (range $=15-71 \mathrm{~min}$ ); for family caregivers, the average duration was $36 \mathrm{~min}$ (range $=20-70 \mathrm{~min}$ ).

\section{Procedure}

Hospital and university ethics committees approved the study. After informed consent was obtained, Benjamin Turner arranged a time to conduct confidential separate interviews with participants with ABI and their family caregivers. Predischarge interviews were conducted during the week before a participant's discharge and were typically conducted in person at the hospital. The 1- and 3-month postdischarge interviews were conducted in person at the participant's own home or at the hospital (32 of 76 interviews) or via telephone for participants living in regional or rural locations (44 of 76 interviews). The mean time between predischarge and the 1-month follow-up interview was 34 days (range $=27-46$ days), and that between predischarge and the 3-month follow-up interview was 100 days (range = 94-117 days).

\section{Data Analysis}

Interview recordings were transcribed verbatim to create written transcripts of the narratives elicited by participants. The primary method of data analysis entailed thematic analysis of the narratives to identify themes, codes, groupings, or categories of statements (Liamputtong \& Ezzy, 2005). The specific thematic analysis process used for this study was adapted from an approach described by Liamputtong and Ezzy (2005), which incorporates open, axial, and selective coding. Open, axial, and selective coding techniques are commonly used in qualitative studies adopting either phenomenological or grounded theory approaches. In this study, we used these techniques within the context of a phenomenological approach because the study was centered on participants' subjective or lived experiences. Participant statements were thematically analyzed using these three stages of coding, with the assistance of the software package NVivo 7 (Bazeley, 2007). The aims and specific steps undertaken within each stage of coding are outlined in Table 3.

We used four strategies throughout the data analysis process to enhance the rigor or trustworthiness of the findings:

- Triangulation of data sources (i.e., two participant groups);

- Consensus coding as outlined in Table 2; 


\begin{tabular}{|c|c|c|}
\hline Coding Stage & Purpose of Coding Stages & Steps Undertaken \\
\hline Open coding & $\begin{array}{l}\text { - The "first run" at coding data. } \\
\text { Involves conceptualizing the data } \\
\text { and noting patterns, themes, } \\
\text { or both. }\end{array}$ & $\begin{array}{l}\text { 1. Reading through all participant interview transcripts. } \\
\text { 2. Rereading all participant interview transcripts and highlighting key words and phrases. }\end{array}$ \\
\hline Axial coding & $\begin{array}{l}\text { - Specifying more rigorously the } \\
\text { emerging themes and codes and } \\
\text { making connections between } \\
\text { these themes and codes. } \\
\text { - Scrutinizing the themes and } \\
\text { codes to ensure that each is fully } \\
\text { elaborated and delineated. }\end{array}$ & $\begin{array}{l}\text { 3. Generating a list of descriptors based on the key words and phrases. } \\
\text { 4. Grouping descriptors with common meanings to develop categories; completed through col- } \\
\text { laboration with all members of the research team. } \\
\text { 5. Consensus coding: Two members of the research team independently coded two interview tran- } \\
\text { scripts (i.e., transcript of } 1 \text { participant with acquired brain injury and of } 1 \text { caregiver) from each } \\
\text { of the three time points using the list of categories with their associated descriptors. } \\
\text { 6. Modifying the list of categories and descriptors according to the results of the consensus coding } \\
\text { process outlined in Step } 5 \text {. } \\
\text { 7. Coding all interview transcripts using the revised list of categories and descriptors. All coded } \\
\text { statements were marked according to their source or origin (i.e., participant with acquired } \\
\text { brain injury or family caregiver) and timing of origin (i.e., predischarge or } 1 \text { or } 3 \text { months post- } \\
\text { discharge). }\end{array}$ \\
\hline Selective coding & $\begin{array}{l}\text { - Using a higher level of specificity } \\
\text { and abstraction than axial coding, } \\
\text { themes and codes are unified to } \\
\text { identify the key issues emerging } \\
\text { from the data. }\end{array}$ & $\begin{array}{l}\text { 8. In-depth reflection of the completed coding process to identify the overarching themes that } \\
\text { emerged from the data. This occurred in collaboration between members of the research team } \\
\text { and in consideration of the studies' aims and objectives. }\end{array}$ \\
\hline
\end{tabular}

- Prolonged engagement of participant contact (i.e., interviews conducted at three separate time points); and

- Reflexivity of coding and theme interpretations (i.e., in-depth collaborative discussion between members of the research team, including two occupational therapists, a speech pathologist, and a neuropsychologist; Patton, 2002).

\section{Results}

The open and axial coding components of the thematic analysis process yielded 34 main categories (see the Appendix), which collectively represent the key areas of importance relevant to the transition phase from the perspectives of participants with ABI and their family caregivers. Of these categories, we identified 8 as having the most relevance to reengagement in meaningful occupations and the aims of this study. Direct references to occupational therapy and occupational therapists are not included in these 8 categories and will form the basis of a separate article. Descriptors for the identified 8 categories are displayed in Table 4.

Further in-depth analysis of the eight main categories, completed through the selective coding process, resulted in the formulation of the following primary themes: desired versus actual participation and the struggle for independence, both of which include several secondary themes. The primary themes and their associated secondary themes represent the issues of most importance to both participants with $\mathrm{ABI}$ and their family caregivers across all eight of the selected main categories. Examples of coded participant statements relevant to the primary themes are displayed in
Table 5, with additional illustrative quotes used in the text. In total, we coded 2,461 participant statements into the eight categories.

\section{Theme 1: Desired vs. Actual Participation}

The first primary theme focuses on the issue of participation during transition and consists of the following secondary themes: desired occupational participation, actual occupational participation, participation facilitating recovery, frustrations in participation, and establishment of a routine and occupying one's time.

Both participant groups identified that the occupations of most importance during the transition phase were returning to driving and work or education. However, for most participants with ABI, driving and work were desired occupations (i.e., occupations that they had previously participated in but were currently unable to do so) as opposed to actual occupations (i.e., occupations that they were actively participating in during the transition phase). Other desired occupations included high-risk interests or hobbies such as motorbike riding and hunting and contact sports such as rugby. Not being able to participate in desired occupations was a source of stress and frustration for many participants with ABI. Many reported that they did not understand why they were not able to participate in these occupations or why it was taking so long to return to active participation in these occupations. Participants further reported feeling uninformed (i.e., receiving no information) or ill informed (i.e., received conflicting information) concerning the process of returning to driving and work or education. This issue is 
Table 4. Summary of Eight Main Categories and Descriptors

\begin{tabular}{|c|c|c|c|c|c|c|c|}
\hline Daily Activities & $\begin{array}{l}\text { Financial and } \\
\text { Legal Issues }\end{array}$ & $\begin{array}{c}\text { Level of } \\
\text { Independence }\end{array}$ & Lifestyle Choices & $\begin{array}{l}\text { Relationships and } \\
\text { Social Activities }\end{array}$ & $\begin{array}{l}\text { Time Use and } \\
\text { Management }\end{array}$ & $\begin{array}{l}\text { Transport and } \\
\text { Driving }\end{array}$ & Work and Education \\
\hline $\begin{array}{l}\text { - Personal } \\
\text { activities of } \\
\text { daily living } \\
\text { - Instrumental } \\
\text { activities of } \\
\text { daily living } \\
\text { - Showering and } \\
\text { bathing } \\
\text { - Household } \\
\text { and domestic } \\
\text { activities } \\
\text { - Household } \\
\text { maintenance } \\
\text { - Interests and } \\
\text { hobbies }\end{array}$ & $\begin{array}{l}\text { - } \text { Managing } \\
\text { finances and } \\
\text { budgeting } \\
\text { - Income sources } \\
\text { - Injury- and } \\
\text { rehabilitation- } \\
\text { related } \\
\text { expenses } \\
\text { - Debt and loans } \\
\text { - Financial strain } \\
\text { - and pressure } \\
\text { - Legal issues } \\
\text { - Charity orga- } \\
\text { nizations and } \\
\text { fund raising } \\
\text { - Being the } \\
\text { provider } \\
\text { - Compensation } \\
\text { and insurance }\end{array}$ & $\begin{array}{l}\text { - Being depen- } \\
\text { dent on others } \\
\text { - Regaining inde- } \\
\text { pendence } \\
\text { - Useful, not } \\
\text { useless } \\
\text { - Being produc- } \\
\text { tive and con- } \\
\text { tributing } \\
\text { - Regaining con- } \\
\text { trol of one's life }\end{array}$ & $\begin{array}{l}\text { - Decision- } \\
\text { making } \\
\text { processes } \\
\text { - Restrictions } \\
\text { - "Not being } \\
\text { allowed" } \\
\text { - Overprotec- } \\
\text { tiveness } \\
\text { - Losing control } \\
\text { - Feeling held } \\
\text { back } \\
\text { - Proving myself } \\
\text { to others } \\
\text { - Injury-related } \\
\text { restrictions } \\
\text { - Supervision } \\
\text { - Setting rules } \\
\text { and boundaries } \\
\text { - Enforcing rules } \\
\text { and boundaries } \\
\text { - Letting go }\end{array}$ & $\begin{array}{l}\text { - } \text { Relationship } \\
\text { strain } \\
\text { - Intimate } \\
\text { relationships } \\
\text { - } \text { Relationship } \\
\text { breakdown } \\
\text { - } \text { Managing } \\
\text { disputes and } \\
\text { - } \text { arguments } \\
\text { - Being tolerant } \\
\text { of others } \\
\text { - Social } \\
\text { - } \text { situations } \\
\text { - Getting along } \\
\text { - Isith others } \\
\text { Isolation and } \\
\text { loneliness } \\
\text { - Strengthening } \\
\text { relationships } \\
\text { - Developing new } \\
\text { friendships } \\
\text { - Going to parties } \\
\text { and clubs }\end{array}$ & $\begin{array}{l}\text { - Having some- } \\
\text { thing to do } \\
\text { - Boredom } \\
\text { - Developing a } \\
\text { routine } \\
\text { - Perceptions of } \\
\text { time use } \\
\text { - Keeping busy } \\
\text { - Time expecta- } \\
\text { - tions } \\
\text { - Slowness } \\
\text { - Time availability }\end{array}$ & $\begin{array}{l}\text { - Having my } \\
\text { license taken } \\
\text { away } \\
\text { - Catching buses } \\
\text { - Driving } \\
\text { unlicensed } \\
\text { - } \text { Returning to } \\
\text { driving } \\
\text { - Public transport } \\
\text { - Driving assess- } \\
\text { - } \text { ments } \\
\text { Medical clear- } \\
\text { ance to drive }\end{array}$ & $\begin{array}{l}\text { - Maintaining } \\
\text { contact with } \\
\text { employers } \\
\text { - } \text { Returning to } \\
\text { work } \\
\text { - Exploring work } \\
\text { options } \\
\text { - Shifting career } \\
\text { focus } \\
\text { - Returning to } \\
\text { - } \text { studies } \\
\text { - } \text { Work trials } \\
\text { - } \text { Redified duties } \\
\text { - Wage negotia- } \\
\text { - } \text { tions } \\
\text { - Family busi- } \\
\text { - } \text { nesses } \\
\text { Retirement }\end{array}$ \\
\hline
\end{tabular}

reflected in the following quote from a family caregiver (numbers throughout refer to participant numbers):

Caregiver (C): It's really affecting him not having his license, and I think because we've been told so many different things of how you go about getting the license back, that is really annoying him. But I mean, I've tried to tell him don't worry about it at this stage. (C16, 3month interview)

Occupations that participants with ABI commonly engaged in during the transition phase included personal activities of daily living, general domestic activities and other household maintenance tasks, parental responsibilities, general health and fitness activities, and lower-risk interests or hobbies (e.g., reading, arts and crafts, playing musical instruments). Despite wanting to do more by engaging in the desired occupations, participants reported that returning home had been beneficial to their ongoing recovery. Most stated that their recovery had continued to improve since coming home.

Interviewer (I): How has coming home influenced your recovery?

Participant (P): It's sped it up a lot. . . . I'm not saying I'm ready to go back to work today but like maybe another month or 2 . . . Like 3 weeks ago, I thought no; there's no way in the world I would go back to work for quite a while. But, yeah, being home ... that's made it a little bit quicker. (P9, 1-month interview)

Although participants with ABI typically viewed the home environment as a key factor in this improvement, many family caregivers reported that participation in meaningful occupations was likewise a fundamental element of recovery gains.

I: How has coming home influenced her recovery?

C: I think it's still improving. Certainly we've got her back into [horse] riding, which was a recreation that she loved beforehand and the functional use of her hand [in] doing that, you know, she was neglecting it a bit until she went horse riding, so ... I can see an improvement there.

(C8, 1-month interview)

Many participants with $\mathrm{ABI}$ also reported frustration with the processes associated with actual occupational participation during transition. These frustrations were typically a result of slowness or fatigue experienced during task completion. Participants commonly reported taking more time to do things or finding themselves more tired than usual during the initial few months at home.

$P$ : The most difficult thing is the slowness with which I can do everything because of my physical slowness of movement and the tiredness which comes with doing physical things. (P3, 1-month interview)

Some participants also reported frustration after attempting tasks and either being unable to complete them or experiencing higher levels of difficulty than they had previously anticipated. Family caregivers reported that it was distressing when their loved ones failed in their attempt to complete specific tasks, but they also understood that failure often facilitated insight into the effects of their injury, which was viewed to be a necessary part of the adjustment process. 


\begin{tabular}{|c|c|}
\hline Themes & Coded Participant Statements \\
\hline \multicolumn{2}{|c|}{ Primary Theme 1: Desired versus actual participation } \\
\hline \multirow[t]{4}{*}{ Desired occupational participation } & I: Do you have any goals in your therapy at the moment? \\
\hline & $\mathrm{P}$ : Just to get back to work that is all I really care about. (P1,1-month interview) \\
\hline & I: What do you feel will be the focus for the next couple of months? \\
\hline & $\begin{array}{l}\text { C: Probably doing everything we can do to get him back to work, and I know he might not go back to work for } 6 \text { months but } \\
\text { just get him on the track where it feels like it's working towards a goal. Just trying to keep him happy and positive until he, if } \\
\text { he can, get back to work. (C4, 3-month interview) }\end{array}$ \\
\hline \multirow[t]{3}{*}{ Actual occupational participation } & I: How did it feel to be at home? \\
\hline & $\begin{array}{l}\text { P: Oh it's great and I felt really good, you know, like I feel really good and I'm cooking dinner every night and everything and } \\
\text { bathing my little girl all right and feeding my horses. (P9, 1-month interview) }\end{array}$ \\
\hline & $\begin{array}{l}\text { C: He has been certainly helping me out a bit which is nice, he's done a bit of painting as you probably saw.... He's been } \\
\text { doing bits and pieces and not exhausting himself too much but sort of taking it slowly, which has been really great. Probably } \\
\text { other than that not an awful lot, just sort of pottering about the house and just general household duties. (C15, 3-month } \\
\text { interview) }\end{array}$ \\
\hline \multirow[t]{2}{*}{ Participation facilitates recovery } & I: How do you feel they are going in their recovery? \\
\hline & $\begin{array}{l}\text { C: I do see that they are improving. I think each day is better for [participant with acquired brain injury (ABI)], especially } \\
\text { because she's able to do a little bit more every day, and she does a lot of things on the phone that she wants done and she's } \\
\text { very good in all those areas. She's getting around a little bit more every day. (C12 \& C13, 1-month interview) }\end{array}$ \\
\hline Frustrations in participation & $\begin{array}{l}\text { C: We needed the oil changed on our car last week and I said to him, what oil do I need? ... So we went out to the garage. } \\
\ldots \text { Now normally he would just go bang and spit it out you know, but he spent probably } 10 \text { minutes, maybe even a little } \\
\text { longer, going around the garage and in the car ... and he just couldn't find it, he got so frustrated, slammed doors, came } \\
\text { inside, back on the computer, you know and that was it. (C5, 1-month interview) }\end{array}$ \\
\hline \multirow{4}{*}{$\begin{array}{l}\text { Establishing a routine and } \\
\text { occupying one's time }\end{array}$} & I: What have been the most difficult things about coming home? \\
\hline & $\begin{array}{l}\text { P: Just finding stuff to do. Like there's plenty of stuff to do like we've got a PS3 and we've got about } 100 \text { DVDs and the } \\
\text { Internet and everything, so there's plenty of things to do as such, but just, I just feel out of place. . . I've just got to get } \\
\text { back into a routine. (P11, 1-month interview) }\end{array}$ \\
\hline & I: How have things been? \\
\hline & $\begin{array}{l}\text { C: Good I suppose yeah he's, um, still having like his sleeps like during the day and stuff, and trying to keep him occupied I } \\
\text { suppose is probably the hardest thing. (C20,1-month interview) }\end{array}$ \\
\hline
\end{tabular}

Primary Theme 2: Struggle for independence

Embracing the freedom of being I: What are the best things about being at home? at home

P: Freedom. To be able to do what I want to do when I want to do it. . . If I want to watch TV, I can sit down in the chair and watch TV. Whatever channel I want, I can put it on. I can go and have a shower at midday; I can go and have a shower at 2 o'clock in the afternoon. (P2, 1-month interview)

I: How were things when [participant with $\mathrm{ABI}$ ] first came home?

C: Good! He got straight in, he got his horses in, he was grooming them, he started shoeing one of them, yeah, he just got really stuck back into everything. (C4, 1-month interview)

Dealing with restrictions I: What has been the most difficult thing about coming home?

P: I'm not allowed to do too much, you know. I can't get in the car, I'm not allowed to drive yet, I can't get in the car and go and visit someone. (P9, 1-month interview)

C: He's going a little stir crazy at times, but he is definitely still doing things so that's good.

I: What's been making him go "stir crazy"?

C: I think it's more to do with just because he can't do what he used to do. . . . He has certainly been getting frustrated at the fact that he isn't able to drive at that point in time and he can't get out there and grab the lawnmower, which is kind of ridiculous because the grass isn't growing at the moment anyway. Just those sorts of things he would normally be able to get out there and do are still limitations for him, there are still things he's not allowed to go and do. (C15, 3-month interview)

Feeling useful and wanting to contribute

Relationships and the struggle for independence
I: How important is the issue of going back to work?

$\mathrm{P}$ : Well in some ways it doesn't matter particularly in terms of financially we are not too badly off, but that still means I will be dependent on [wife's] wage. ... At the moment we should be able to continue financially okay on just the one wage, but I just would like to be making a contribution preferably from home but just how long it takes before I can start doing that I don't know. (P3, 3-month interview)

I: What about family relationships? How are things going that way?

$\mathrm{P}: \mathrm{F}^{\star \star \star * \star}$. That's the only word for it. I don't speak to my family anymore apart from [partner] and my daughter. Mum and dad, my sister, nah, nah, gone, done. (P1, 3-month interview)

I: What do you feel has had the biggest impact on your recovery?

P: Would be the support from my family and friends and also work as well? (P11, 3-month interview)

Note. $\mathrm{I}$ = interviewer, $\mathrm{P}=$ participant; $\mathrm{C}=$ caretaker; numerals = participant numbers. 
Other key elements of transition success identified by participants with $\mathrm{ABI}$ and their family caregivers included establishing routines or schedules and occupying one's time. Establishing a routine was initially often difficult for participants with $A B I$ who transitioned from the highly structured and routine-driven environment of a rehabilitation unit to the relative freedom of home. For some participants, the impact of this change in environment, coupled with the reality of not being able to engage in their desired occupations, led to a relatively unproductive lifestyle in which the main activity of their day involved little more than watching television or playing computer games.

I: What is a typical day like for you?

P: Get out of bed, watch TV, get up, have breakfast, sit back down, and watch TV. Go out and get the mail at half past 11. Go back in, watch TV, get up, and have lunch at half past 12, quarter to one, watch TV until 4:00 or 5:00 or 6:00 and get up and have tea with the family.

That's me basic day. (P2, 3-month interview)

For most participants, however, the impact was buffered by family caregivers, who typically adopted the role of developing routines and ensuring people had something to do to occupy their time. However, in assuming this role, family caregivers also faced the challenge of establishing new routines in their own lives as they, too, began the process of resuming important occupational roles such as returning to the workforce. Caregivers commonly expressed feeling fatigued and stressed as they struggled to cope with the demands of the caregiving role.

I: How has the 1st month at home been?

C: Very, very tiring. Just trying to establish a routine, for me trying to get back to work and fit in appointments and it's been sort of like, life is on hold for a while. Yeah, quite tiring and quite stressful just coping with everything. (C7, 3-month interview)

\section{Theme 2: Struggle for Independence}

The second primary theme highlights the struggle for independence experienced by participants with $\mathrm{ABI}$ and the differing perspectives of participants with $\mathrm{ABI}$ and their family caregivers concerning this issue. The struggle for independence includes the following secondary themes: embracing the freedom of being at home, dealing with restrictions, feeling useful and wanting to contribute, and dealing with relationship support or strain.

Returning home was typically heralded by participants with $\mathrm{ABI}$ as a newfound freedom and perceived as an important step in the process of resuming a normal life. Participants commonly expressed excitement at the prospect of discharge, closely followed by feelings of relief at the time of discharge. Many participants with $\mathrm{ABI}$ reported embracing this new- found freedom during the initial few weeks at home by resuming participation in as many preinjury activities as possible. Of importance to participants with $A B I$ was the freedom of "being able to do things that I want to do when I want to do it" (P7, 3-month interview). However, this perceived freedom was often short lived, because participants quickly discovered a range of barriers and restrictions that hindered their pursuit of independence. Overcoming the barriers and restrictions, which included both formal and informal constraints, posed the greatest challenge to the struggle for independence.

Formal restrictions participants reported as being imposed on them during the transition phase included the legal issue of medical clearance to return to driving and work, along with other safety recommendations to avoid alcohol and the operation of power equipment or machinery. Not being able to drive or work affected participants' independence in other areas of life such as social participation. Furthermore, participants reported that not being able to engage in these occupations meant that they were dependent on others, principally family members, for transportation needs and, in some cases, financial assistance.

P: I'm keen as mustard to start driving again for the simple thing [that] it gives you a bit more independence. At the moment, I have to rely on [my wife] or taxis to get around, and if I want to go out to my farm ... I have to wait for someone to be able to drive me out there. (P18, 1-month interview)

Clear disparities were identified between participants who had some form of insurance coverage or legal medical claim and those who did not. Those with such coverage generally had greater financial security and were more supported in understanding the processes involved in returning to driving and work. Consequently, those with coverage were typically less anxious about returning to these occupations.

Informal restrictions described by participants were typically the supervisory conditions reported to be imposed on them by family members. Although these conditions differed among participants, they included conditions such as not being "allowed" to be left at home alone or not being able to go out alone and were typically perceived by participants with $A B I$ as their family caregiver's attempts to protect them from further injury or harm. This perception was validated by family caregivers, who commonly described the struggle they had in enabling participation while at the same time holding people back from activities they viewed as potentially dangerous or detrimental to their ongoing recovery. Family caregivers understood the need for the participants with $A B I$ to be active and regain control of their lives, but often felt that complete control was too much for them to manage, especially during the first 1-2 months at home. For 
example, the following statement highlights the difficulty one caregiver experienced in deciding when it was time to let go:

C: It's probably a little bit hard to let go because I have been so involved in it and, you know, organizing things and that. I've had to pull back a bit because I don't want him to be always reliant on me. I need him to stand on his own two feet, but I have to still be there to support him so he doesn't fall backwards. ... I'm still a little bit, not anxious, it's just a little bit awkward letting go. (C11, 1-month interview)

The impact of these restrictions and the struggle for independence often led to situations in which participants with $\mathrm{ABI}$ demonstrated resistance in an attempt to regain control. Examples included running away from home and driving without medical clearance. The motivation for resisting restrictions often appeared to be the pursuit of greater independence and in some cases seemed to reflect a clear desire to rebel.

P: I've been driving unlicensed. ... Yeah, well, I can't just sit out on the farm here and not go anywhere you know, I have to go and get food and stuff like that.

I: How long have you been driving unlicensed?

P: Since I got out of hospital. (P19, 3-month interview)

For other participants, the tendency to resist restrictions appeared to represent an underlying desire to feel useful or to contribute. The loss of meaningful life roles, including those of being an employee or worker and a financial provider for one's family, was highlighted by both participants with $\mathrm{ABI}$ and their family caregivers as a key source of emotional distress and frustration during the transition phase. Some participants reported compensating for the loss of certain occupational roles by adopting new meaningful roles (e.g., household management), and others felt that doing so could undermine their efforts to resume previously held and valued occupational roles. Ultimately, feeling useful and contributing were viewed as important elements necessary for adjustment and integral to transition success.

P: I actually went to the bike shop up the road just to explain my situation and asked if I could volunteer, just help them out, just anything to kill the time, to feel useful, and as I say I get money from the income support thing you know so it's not like they are paying for it. I just want to be useful. That is the main thing; I have never been this useless. (P1, 3-month interview)

A further consequence of imposed restrictions and the struggle for independence was strained relationships. Family and friendship networks were seen to be invaluable sources of support during transition, especially for emotional adjustment and enabling reengagement in meaningful occupations. Despite this, the support provided by family caregivers was sometimes deemed excessive by participants with ABI and viewed as overprotective or controlling. In acknowledging the association between overprotectiveness and relationship strain, many family caregivers described the challenge they experienced in enabling freedom while maintaining their own sense of control through supervision. Disputes and arguments about what participants with $\mathrm{ABI}$ were allowed to do were commonly reported by both participants with $\mathrm{ABI}$ and their family caregivers.

C: I just have to be careful all the time as far as [participant with $A B I]$ is concerned. She thinks I'm in control and I don't feel that I am at all. ... I give them lots of time to themselves together. I don't even go over to their apartment. . . . I sort of keep to myself but watch over them at the same time, but I don't intrude or anything like that. (C12 and C13, 3-month interview)

\section{Discussion}

We identified the two primary themes of desired versus actual participation and the struggle for independence that were most pertinent to reengagement in meaningful occupations during the transition from hospital to home for people with ABI and their family caregivers. Specifically, we identified a clear incongruity between occupations that participants wanted to engage in and those in which they were actually engaging in during the transition. This discrepancy, along with various formal and informal restrictions that participants perceived were imposed on them, presented the most significant challenge to the pursuit of independence during the transition phase.

In relation to the study's first aim, the findings indicated that resuming driving and working were the key occupations of importance to participants with $\mathrm{ABI}$ during transition. Despite this, few participants were able to return to these occupations. Instead, participants were more commonly engaged in general household, community, or social activities. Several previous studies have explored the issue of occupational participation after $\mathrm{ABI}$ and have demonstrated that people typically experience difficulties with reengagement, and consequently participation is limited (Gage et al., 1997; Powell, Temkin, Machamer, \& Dikmen, 2007; Turner et al., 2007). Our findings extend the literature by providing in-depth insight into the process of reengagement during the early transition phase and by highlighting the discrepancy between desired and actual occupational participation.

In terms of the study's second aim, to explore people's lived experiences of reengagement in meaningful occupations after $\mathrm{ABI}$, the findings revealed varied perspectives regarding the benefits of participation. Specifically, the 
results suggest that reengagement or participation in meaningful occupations during transition is to some extent a mixed blessing or double-edged sword. However, the process facilitates recovery, aids in the establishment of routines, and enables people to occupy their time. However, reengagement was shown to lead to frustration (i.e., about deficits experienced or the inability to resume desired occupations), restrictions to independence, and relationship strain. Although some of these issues have been previously identified in the literature (McCabe et al., 2007; McColl et al., 1998, 1999), our findings particularly highlight some key elements integral to early transition success, such as facilitating recovery through participation, fostering feelings of usefulness, enhancing people's use of time, and assisting people in managing perceived restrictions. Moreover, we identified important issues relevant to family caregivers during the transition phase, such as the stress and strain of the caregiving role and their own support needs.

\section{Clinical Implications}

These findings have various implications for occupational therapy practice, particularly in relation to the process of supporting clients' reengagement in meaningful occupations during the transition period. The findings provide therapists with greater insight into the issues encountered by people with $\mathrm{ABI}$ as they attempt to regain independence during the transition from hospital to home. For example, the identified discrepancy between desired and actual occupational participation has particular relevance for client-centered goal setting. Given that goal setting has been shown to influence client motivation and participation in rehabilitation (Carlson, 1996; Trombly, Radomski, \& Davis, 1998; Trombly et al., 2002), how therapists reconcile the different perspectives on achievable occupational pursuits and establish meaningful yet realistic client-centered goals is likely to have a strong bearing on therapy outcomes. Although not wanting to either destroy a person's hope or promote false hope, therapists need to ensure that clients' desired occupational outcomes are validated and incorporated into the development of therapy plans.

In this study, we also highlighted areas of support that both people with $\mathrm{ABI}$ and their family caregivers perceived to be lacking. Specifically, provision of information or education is needed on

- The process of returning to work or education and driving,

- Ways to establish routines and structure one's time,

- Ways for managing stress and frustration, and

- Ways to cope with formal and informal restrictions.

This information needs to be provided to both people with $\mathrm{ABI}$ and their family caregivers not only before hospital discharge, but also during the initial few weeks or months at home. Given their broad expertise and holistic view of health, occupational therapists are well placed to provide information and further assist clients and families with addressing the identified issues.

This study's results also demonstrated that participation in meaningful occupations was perceived to enhance functional recovery during transition. This finding underscores the importance of encouraging and facilitating participation in meaningful occupations, which could be addressed within the therapy context by selecting relevant real-life tasks for clients to participate in during therapy sessions. Moreover, the identified disparity between desired and actual occupational participation highlights the need for therapists to select tasks that relate to their client's desired goals, to facilitate an understanding of how therapy tasks relate to desired goals, or both. For example, a client may have a goal of resuming driving yet be unable to actively participate in activities or tasks that directly relate to this goal because of various cognitive and physical deficits. Highlighting how improvement of cognitive and physical skills is necessary for returning to driving may facilitate improved client motivation for participating in cognitive and physical rehabilitation during therapy sessions (Fleming et al., 2006).

\section{Limitations of the Study}

Although this study's results highlight many issues relevant to clinical practice, some methodological considerations need to be acknowledged. First, the study was conducted in a specific setting and cultural context. Consequently, the data are not transferable. Second, the study focused on the early transition phase and therefore did not capture how people's experiences may vary over an extended period of time (i.e., through a 6- or 12-month follow-up). Finally, the study did not incorporate therapists' perspectives, which may provide a more comprehensive understanding of issues affecting the process of reengagement during the transition phase. Despite these issues, the study used a prospective longitudinal design with three data collection points and yielded clinically relevant findings pertinent to the process of reengagement in meaningful occupations during transition.

\section{Future Research and Conclusion}

In this study, we aimed to explore the lived experiences of people with $A B I$ and their family caregivers on reengagement in meaningful occupations during the transition phase. The findings highlight that although there are many benefits of reengagement, which include facilitating functional recovery and establishing routines, people often experience frustration because of their deficits and their inability to reengage in desired occupations. They also perceive various barriers or 
restrictions to regaining independence and experience relationship strain. The clinical practice implications of these findings relate to client-centered goal setting, contexts or environments in which therapy occurs, and the provision of information to individual people and families. We recommend that future research focus on investigating the effectiveness of occupational therapy interventions during transition, including therapy approaches that incorporate client-centered goal setting, home-based therapy, client and family education, and support to establish routines and manage time.

\section{Appendix. Summary of Main Categories Generated From Thematic Analysis Process}

\begin{tabular}{|c|c|c|}
\hline \multirow[b]{2}{*}{ Main Category } & \multicolumn{2}{|c|}{ Statements From } \\
\hline & $\begin{array}{c}\text { Participants } \\
\text { With Acquired } \\
\text { Brain Injury }\end{array}$ & $\begin{array}{c}\text { Family } \\
\text { Caregivers }\end{array}$ \\
\hline Accommodation or Living Situation & 51 & 45 \\
\hline Acute Care & 35 & 69 \\
\hline Alcohol and Drug Use & 45 & 33 \\
\hline Behavior-Personality & 47 & 120 \\
\hline Cognitive Functioning & 115 & 70 \\
\hline${ }^{\star}$ Daily Activities & 221 & 136 \\
\hline Discharge Preparation & 181 & 102 \\
\hline Education About Injury and Rehabilitation & 26 & 78 \\
\hline $\begin{array}{l}\text { Emotional and Psychological Well-Being } \\
\text { and Adjustment }\end{array}$ & 202 & 215 \\
\hline Family and Caregiver Issues & 283 & 424 \\
\hline${ }^{*}$ Financial and Legal Issues & 195 & 163 \\
\hline General Health and Fitness & 59 & 33 \\
\hline Home Environment & 55 & 53 \\
\hline Hospital Environment & 133 & 90 \\
\hline Injury and Accident & 82 & 72 \\
\hline *Level of Independence & 40 & 66 \\
\hline Life at Home & 185 & 67 \\
\hline Life or Death & 9 & 10 \\
\hline *Lifestyle Choices & 117 & 130 \\
\hline Living With a Disability & 30 & 12 \\
\hline Medical Management & 96 & 61 \\
\hline Motivation and Self-Esteem & 70 & 42 \\
\hline Other Injury-Related Deficits & 50 & 27 \\
\hline Recovery & 206 & 128 \\
\hline Rehabilitation & 573 & 227 \\
\hline *Relationships and Social Activities & 216 & 181 \\
\hline Relaxation & 16 & 20 \\
\hline Service Utilization & 68 & 98 \\
\hline Service-Related Issues & 141 & 173 \\
\hline Sleep and Fatigue & 67 & 43 \\
\hline Speech and Communication & 26 & 18 \\
\hline${ }^{*}$ Time Use and Management & 154 & 72 \\
\hline${ }^{*}$ Transport and Driving & 235 & 121 \\
\hline *Work and Education & 290 & 125 \\
\hline Total & 4,319 & 3,324 \\
\hline
\end{tabular}

${ }^{*}$ Main categories included in the current study.

\section{Acknowledgments}

The completion of this study was supported by an Australian Post-Graduate Award held by Benjamin Turner. We also gratefully thank the staff in the Brain Injury Rehabilitation Unit at the Princess Alexandra Hospital. Our gratitude is also extended to the participants and their families.

\section{References}

American Occupational Therapy Association. (1995). Position paper: Occupation. American Journal of Occupational Therapy, 49, 1015-1018.

Anson, K., \& Ponsford, J. (2006). Coping and emotional adjustment following traumatic brain injury. Journal of Head Trauma Rehabilitation, 21(3), 248-259.

Barras, S. (2005). A systematic and critical review of the literature: The effectiveness of occupational therapy home assessment on a range of outcome measures. Australian Occupational Therapy Journal, 52(4), 326-336.

Bazeley, P. (2007). Qualitative data analysis with NVivo. London: Sage.

Carlson, J. (1996). Evaluating patient motivation in physical disabilities practice settings. American Journal of Occupational Therapy, 51(5), 347-351.

Crepeau, E., Cohn, E., \& Schell, B. (2008). Willard and Spackman's occupational therapy (11th ed.). Philadelphia: Lippincott Williams \& Wilkins.

Fleming, J., Connell, J., Tooth, L., \& Strong, J. (2002). A comparison of adjustment and self-awareness in adults after traumatic brain injury and spinal cord injury: The transition from hospital to community. Journal of Cognitive Rehabilitation, 20(3), 28-36.

Fleming, J., Lucas, S., \& Lightbody, S. (2006). Using occupation to facilitate self-awareness in people who have acquired brain injury: A pilot study. Canadian Journal of Occupational Therapy, 73(1), 44-55.

Gage, M., Cook, J., \& Fryday-Field, K. (1997). Understanding the transition to community living after discharge from an acute care hospital: An exploratory study. American Journal of Occupational Therapy, 51, 96-103.

Gray, J. (1998). Putting occupation into practice: Occupation as ends, occupation as means. American Journal of Occupational Therapy, 52, 354-364.

Law, M., Baptiste, S., Carswell, A., McColl, M., Polatajko, H., \& Pollock, N. (1998). The Canadian Occupational Performance Measure (3rd ed.). Ottawa, Ontario: CAOT Publications.

Liamputtong, P., \& Ezzy, D. (2005). Qualitative research methods (2nd ed.). Hong Kong: Oxford University Press.

McCabe, P., Lippert, C., Weiser, M., Hilditch, M., Hartridge, C., \& Villamere, J. (2007). Community reintegration following acquired brain injury. Brain Injury, 21(2), 231-257.

McCarthy, M., Dikmen, S., Langlois, J., Selassie, A., Gu, J., \& Horner, M. (2006). Self-reported psychosocial health among adults with traumatic brain injury. Archives of Physical Medicine and Rehabilitation, 87(7), 953-961.

McColl, M., Carlson, P., Johnston, J., Minnes, P., Shue, K., Davies, D., \& Karlovits, T. (1998). The definition of com- 
munity integration: Perspectives of people with brain injuries. Brain Injury, 12(1), 15-30.

McColl, M., Davies, D., Carlson, P., Johnston, J., Harrick, L., Minnes, P., \& Shue, K. (1999). Transitions to independent living after ABI. Brain Injury, 13(5), 311-330.

Paterson, B., \& Scott-Finlay, S. (2002). Pearls, pith, and provocation: Critical issues in interviewing people with traumatic brain injury. Qualitative Health Research, 12(3), 399-409.

Patton, M. Q. (2002). Qualitative research and evaluation methods (3rd ed.). Thousand Oaks, CA: Sage.

Phipps, S., \& Richardson, P. (2007). Occupational therapy outcomes for clients with traumatic brain injury and stroke using the Canadian Occupational Performance Measure. American Journal of Occupational Therapy, 61, 328-334.

Pierce, D. (2001). Untangling occupation and activity. American Journal of Occupational Therapy, 55, 138-146.

Powell, J., Temkin, N., Machamer, J., \& Dikmen, S. (2007). Gaining insight into patients' perspectives on participation in home management activities after traumatic brain injury. American Journal of Occupational Therapy, 61, 269-278.

Rappaport, M. (2005). The Disability Rating Scale and Coma/ Near Coma scales in evaluating severe head injury. Neuropsychological Rehabilitation, 15(3/4), 442-453.

Schlossberg, N. K. (1984). Counseling adults in transition: Link practice with theory. New York: Springer.
Teasdale, G., \& Jennett, B. (1974). Assessment of coma and impaired consciousness. A practical scale. Lancet, 2(7872), 81-84.

Trombly, C., Radomski, M., \& Davis, E. (1998). Achievement of self-identified goals by adults with traumatic brain injury: Phase 1. American Journal of Occupational Therapy, 52, 810-818.

Trombly, C., Radomski, M., Trexel, C., \& Burrnett-Smith, S. (2002). Occupational therapy and achievement of self-identified goals by adults with acquired brain injury. American Journal of Occupational Therapy, 56, 489-498.

Turner, B., Fleming, J., Cornwell, P., Worrall, L., Ownsworth, T., Haines, T., et al. (2007). A qualitative study of the transition from hospital to home for individuals with acquired brain injury and their family caregivers. Brain Injury, 21(11), 1119-1130.

Turner, B., Fleming, J., Ownsworth, T., \& Cornwell, P. (2008). The transition from hospital to home for individuals with acquired brain injury: A literature review and research recommendations. Disability and Rehabilitation, 30(16), 1153-1176.

Uniform Data System for Medical Rehabilitation. (1999). The guide for the Uniform Data Set for Medical Rehabilitation (including the FIM ${ }^{\mathrm{TM}}$ instrument), Version 5.1. Buffalo, NY: Author. 
Reproduced with permission of the copyright owner. Further reproduction prohibited without permission. 